\title{
MOOCs and their Influence on Higher Education Institutions: Perspectives from the Insiders
}

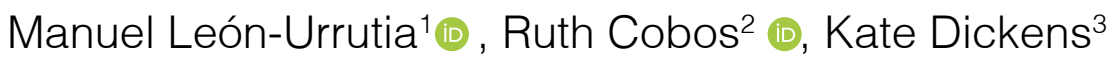 \\ IInstitute for Learning Innovation and Development, University of Southampton, UK \{m.leon-urrutia@soton.ac.uk\} \\ 22Autonomous University of Madrid, Spain \{Ruth.cobos@uam.es\} \\ 3Institute for Learning Innovation and Development, University of Southampton, UK \{Kate.Dickens@soton.ac.uk\} \\ Received on 15 June 2017; revised on 12 September 2017; accepted on 18 September 2017; published on 15 January 2018
}

\begin{abstract}
Since Massive Open Online Courses (MOOCs) became a global phenomenon in 2012, there has been constant evolution in the way Higher Education Institutions (HEls) make sense of them. HEls embracing MOOCs have dedicated a variety of human resource to this venture. Only in a minority of cases, staff have been appointed exclusively to this role. In all other cases, MOOC related tasks have been allocated to professionals who were already performing other educational tasks. This article contains a study that captures the experiences of these professionals in a Spanish university and a British university, as relates to their involvement in MOOCs. Interviews and group sessions were conducted to ascertain the influence of MOOCs in their practice, and in their opinions about the role of MOOCs in their institutions. The results seem to suggest that participants have positive attitudes towards incorporating MOOCs at the university, although they demand a serious bet for this educational approach from the strategic decision makers in the institutions.
\end{abstract}

KEYWORDS: COMPUTER USES IN EDUCATION, UNIVERSITIES, EDUCATIONAL POLICIES, TEACHING METHOD INNOVATIONS, DIGITIZATION

\section{INTRODUCTION}

Higher Education Institutions (HEIs) have been offering Massive Open Online Courses for a few years, long enough to accumulate experience that allows a sufficiently grounded assessment of their challenges and opportunities. Daniel (2012) places the start of the MOOC movement in 2008, when David Cormier coined the term referring to a course about connectivism led by George Siemens. Later on, in 2012, the platform Coursera and edX entered the scene, and MOOC production and uptake boomed to such an extent that the New York Times called that year "The Year of the MOOC" (Pappano, 2012). Such hype was followed by a spread of sceptical voices the year after (Kolowich, 2014; Hollands, 2014; Sharrock, 2015), although the steady growth in recent years seems to indicate that the MOOC movement is not going to fade away for the moment (Shah, 2017).

\section{*To whom correspondence should be addressed:}

University of Southampton

University Road, Southampton, SO17 1BJ, United Kingdom
The strategic motivations for offering MOOCs in universities have been widely discussed globally, such as in Australia (O'Connor, 2014), Europe (Jansen \& Schuwer, 2015), and in the US (Hollands \& Thirthali, 2014). It has been suggested in a comparative study that HEIs in Europe seem to be keener on MOOCs than those in the US (Jansen, Schuwer, Teixeira, \& Aydin, 2015). The same study suggests pedagogical innovation as the main motivation, rather than an innovation in the business model. Another study identified educational innovation as the main motivation for universities to offer MOOCs, as reported in specialist Higher Education media (León, White, \& White, 2016), as well as a significant factor in the news media discourse (Bulfin, Pangrazio, \& Selwyn, 2014).

A significant proportion of the discussions about the evolution of MOOCs in HEIs have their grounds in the perceptions of commentators in education technologies, as well as in the voices of senior management in universities, who are not necessarily directly involved in MOOC production or delivery. For example, the Babson Research Group runs surveys in American universities every year (see Allen \& Seaman, 2015)

Many of these discussions about the direction MOOCs are taking are based on the impressions of learning technologies commentators, and on surveys often addressed to professors and decision makers who are not always involved in the production of these courses, e.g. the yearly surveys carried out in the US (ibid), where the participants surveyed are 'chief academic officers' (p.3). This is also the case of Jansen's survey in Europe (Jansen $\&$ Schuwer, 2015), where the questions written are to be answered in representation of an institution. There is, however, not so much work done on the personal experiences of those involved in the day-to-day development of MOOCs i.e. learning designers, lecturers, professors, postgraduate students, administrators, legal teams, etc. This study aims to find out what these professionals think about MOOCs. In order to determine what the influence of MOOCs is in HEIs from the perspectives of this stakeholder group, the following research questions were formulated:

- How do MOOCs influence HEIs' institutional strategy?

- How do MOOCs influence HEIs' staff practices?

- How do MOOCs influence the current HE landscape?

However, the scope was considered too wide to be reflected in this paper, and the focus was narrowed to topics related to the institutional strategy, generating the following four sub-questions: 
- What opportunities do staff involved in MOOCs identify for their institutions?

- What challenges are faced when developing these MOOCs?

- What is the role of MOOCs in the digital transformation of such institutions?

- What are the needs and demands of staff involved in MOOC development?

\section{METHODOLOGY}

\subsection{The participant institutions}

This study was carried out in a British university, and a Spanish university. The British university (i1) joined the FutureLearn MOOC platform in 2013. As of May 2017, this university offers 15 MOOCs, and has 3 more in the pipeline. Many of these MOOCs have run several times, ranging from 11 runs to 1 run. In the second half of 2016 the enrolment numbers reached half a million. The production team is composed of a fully dedicated programme lead, who, coordinates partly dedicated learning designers, academics, multimedia producers, legal officers, and administrators. The legal services team, academics, teaching assistance, marketing officers, a multimedia production team, all contribute to the process of MOOC development and implementation. A set of "gateways" governs every stage of this process for quality assurance and legal clearance.

The Spanish university (i2), joined the edX Consortium as a new member in 2014. The institution assembled an interdisciplinary team to support, encourage and lead the creation of MOOCs. Following edX's recommendations, this team is composed of several roles: a director to manage the courses and provide legal advice, marketing, instructional designer, multimedia and information technology staff, to support the creation of the courseware in collaboration with the course instructors; data czar, to define and lead the overall research strategy around course data; $\mathrm{Au}-$ dio-Video (AV) professionals, to create AV materials. Courses are delivered by the instructors and teacher assistants.

So far, this institution has offered several runs of eight MOOCs, and has 4 more in the pipeline. More than 90.000 learners have enrolled on their courses. One of its MOOCs was used by its instructor in a flipped-classroom model.

Both institutions offer a training and support programme for the academics, which supports them in generating effective online educational materials. Moreover, every year instructors and students participate in Curriculum Innovation Projects where they use technology enhanced learning tools in their teaching-learning practices.

Methods

Qualitative methods were used in this project. The data collection was conducted in two main (see figure below) stages with different instruments: the so-called "world cafe" method (Aldred, 2009) in the first stage and first institution (i1), and semi-structured interviews (Newton, 2010) in the second stage and second institution (i2). The chosen analysis method was Template Analysis (King, 1998), a variation of Thematic Analysis by which a set of themes identified by the researchers is used as a template to analyse a dataset. The template in this case was created from the list of responses in stage 1, and was applied to the transcripts of the interviews in stage 2 . The following sections contain a more detailed description of the data collection stages of this project.

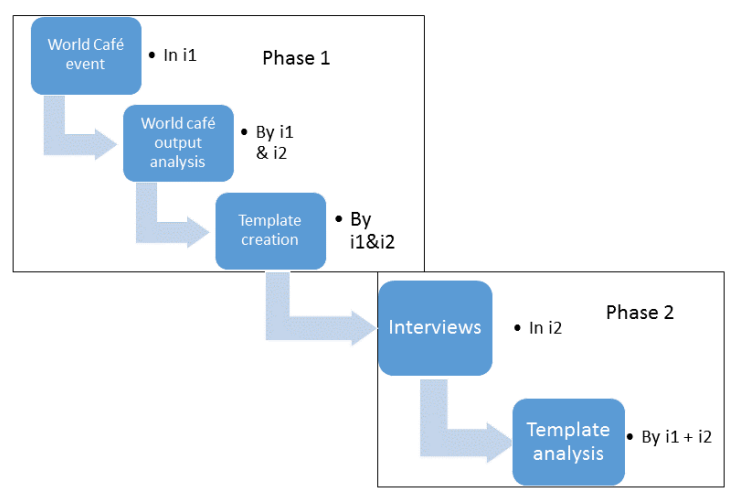

Figure 1. The methodology process

\subsubsection{Stage 1: The World Cafe}

A full-day event was organised in i1, the second part of which was the World Cafe event. The first part was open to all staff and had the purpose of showcasing the progress made with MOOCs within the institution, and included an invited talk by the CEO of the partnering MOOC platform. In the second part, all members of staff involved in MOOC production and implementation were invited. A total of 34 members of staff attended including core project team, academics, learning designers, mentors, media producers, librarians, members from the legal services team, administrators and a representative from the partnering MOOC platform.

The data was collected through World Cafe (Aldred, 2009), an instrument for data collection aimed at gathering perspectives of large groups of participants in organisations in a reduced amount of time. This method aims to give voice to as many participants as possible, and it is often used to gather insights of all members of staff on matters concerning an organisational change, process, approach, or new technology. The incorporation of MOOCs as an educational technological innovation can therefore be considered a suitable topic of enquiry with the World Cafe approach.

In this method, all participants attend a facilitated event, in which a pleasant environment away from the work routine needs to be set up. In il case, it was a hospitality facility within the University, where refreshments and lunch were provided. In an iterative process, participants were divided into small groups on tables led by a host, of around 5 to 8 , and were invited to discuss a theme, prompted by a question. They were encouraged to share their thoughts by writing on flipcharts. When the question changed, the groups were redistributed to different tables. In il there were four iterations in this process. The questions were formulated with the intention of both extracting as many insights as possible from the participants, and at the same time shedding light on the research questions. These were the following:

What do you think has gone well with the MOOCs at i1? What are we proud of? What has changed in your practice as a result of your involvement in MOOCs?

What challenges have we faced? What did not work well? What did we miss?

From what we know and what we've learned this morning, how can we, as a group, capitalise on the 
opportunities that MOOCs offer? What would you and/ or i1 do differently?

What would be a first or next step for MOOCs at i1- both for you, and /or the wider programme? What would you say the 3 key priorities should be?

The outputs of the participants, in the form of anonymised sentences and drawings represented in flipcharts, were transcribed into one document, which was treated as a list of themes in response to the formulated questions. These themes were distributed in a hierarchic model built from the initial research questions, as shown below (Figure 2):

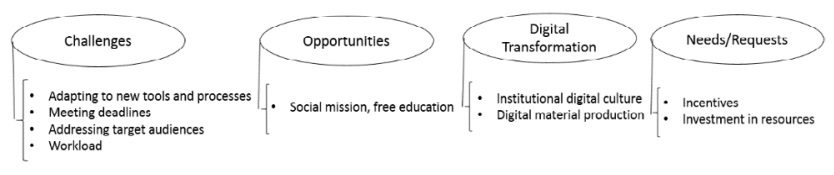

Figure 2. High level themes

The model above represents three levels. There was a fourth level of subthemes represented in the diagram below. In this paper, the focus has been placed on one of the three main branches of the model, namely "to institution", and the Figure 3 represents such part of the model. The influence of MOOCs at institutional level was divided into four categories: challenges, opportunities, digital transformation, and requests.

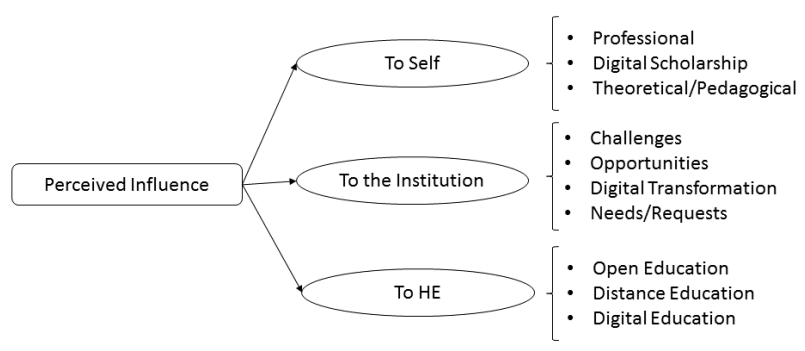

Figure 3. Low level themes

- Challenges: there are challenges inherent to producing educational content in emerging formats such as MOOCs, e.g. reputational risk and lack of certainty about future directions.

- Opportunities: Involvement in MOOCs can bring a variety of opportunities, such as democratisation of education.

- Digital transformation: MOOCs can have a role in the digital transformation of universities from a variety of perspectives

- Needs/requests: those involved in MOOC development have certain demands for a implementing of MOOCs successfully in the institution.

\subsubsection{Stage 2. The interviews at i2}

Eleven short (some 15 minutes) semi-structured interviews were conducted in i2. The participants in the interviews were staff directly involved in MOOC production and delivery: four professors, four lecturers, two $\mathrm{PhD}$ students working as teaching assistants, and an instructional designer. The academics were from varied disciplines, namely philosophy, computer science, chemistry, literature, and law. The questions were the same as those asked in the first stage in i1. The interviews were recorded and transcribed.

The transcripts of these interviews were then analysed against the template created in stage 1 . The analysis was carried out by researchers from both i1 and i2.

\section{RESULTS}

The respondents shared a wide variety of perspectives about how MOOCs influence educational programmes in their institution. These perspectives are presented here in accordance with the template developed for the analysis of this set of interviews:

\subsection{Challenges}

Participants in i2 were given the opportunity to mention the challenges, which they came across when producing or implementing MOOCs. The most relevant to the researchers were:

\subsubsection{Adapting to new tools and processes}

Perhaps the only (or the most salient) difference between the outputs of i1 and i2 is that i2 participants were looking inwards when mentioning challenges, while in il the challenges were mainly attributed to external factors. That is, many of i2 participants mentioned their own lack of experience in the use of tools and processes for producing online learning materials, while in i1 there was little mention in that respect. It should be noted, however, that the different enquiry methods used in i1 and i2 may have had an influence on this particular output. See below the two following examples* in i2: (*translated into English by the researchers)

The main challenge was managing a new tool. I had the teaching experience, and the materials, but I didn't know how to use them (Professor in Literature).

\subsubsection{Meeting deadlines}

This was a recurrently reported challenge both in i1, and i2. This concerns the previous theme about adapting to new processes and tools.

We learned on the go. The majority of our challenges were related to time. Deadlines were approaching and you see the project is not even near to completion. And it is not only about our work in the MOOC office, it is also the contribution from the academics, who have their priorities and pressures too (Learning technologist).

\subsubsection{Addressing target audiences}

Participants in this study mention the difficulty of addressing unknown target audiences. For example, the participant below struggled when attempting to elicit participation from the learning community of the MOOC:

Because you don't see the students, it is very difficult to get them to participate. It is not that they participate a lot in F2F settings, but at least you are in visual contact with them (Mentor in Literature).

This sentiment was shared by other participants, all of them concluding that it is difficult to maintain sustained interactions 
with learners in the MOOCs, as the dialogue would not last in most of the cases. Also, some participants were not impressed by the depth of the conversations:

Most of the comments that I received, especially in the second and third edition of my MOOC, were people introducing themselves and chatting about topics other than that of the MOOC content (Professor in Law).

\subsubsection{Workload}

A highly recurrent issue in the interviews was that of the workload. Some participants commented that, although rewarding in some ways, the efforts involved in creating MOOCs were significant, given that they were made on top of their statutory duties:

I would even dare to say that preparing a MOOC takes more work than preparing a module (Professor in Chemistry).

The workload related to MOOC production resulted in stressful situations for some of the participants, who realised that making a MOOC was more demanding than foreseen, especially when managing a project with tight deadlines and little knowledge of how much time is required into production of educational assets in different format:

We were ten days away from the deadline and we sti11 had so much to do, so many videos to prepare and record, so many questions to write! (Lecturer in Law)

\subsection{Opportunities}

All participants in both $\mathrm{i} 1$ and $\mathrm{i} 2$ had been involved in MOOCs in one way or another. Therefore, it was to be expected that the vast majority of them had a positive attitude towards the institutional engagement in MOOCs.

\subsubsection{Social mission, free education}

This theme was recurrent in participants' responses, when asked about what opportunities producing MOOCs can offer:

...Spanish is spoken by 300 million people. Only by being able to reach all the schools in our country, which could help not only school learners but also school teachers, would be a significant outcome in the specific case of my subject (Chemistry professor).

MOOCs can provide highly affordable access to knowledge to all citizens thanks to technological innovation, in a highly flexible way in terms of dedication, timing, and availability. Education is a fundamental right, and it is in fact my main driver for being involved in MOOCs (Lecturer in Law).

\subsection{Digital transformation}

\subsubsection{Institutional digital culture}

The participants interviewed in this study tended to coincide that MOOCs were not their first significant digital education experience. Most of them had already received digital education experience, especially through the use of VLEs such as Moodle and Blackboard.
I have used Moodle since it was deployed here at the University, as a first order tool, both in my lectures and in my seminars, not only as a simple repository but also as tool for exchanging opinions, activities, and self-learning materials (Professor in Literature).

...After the experience with my own website, Moodle burst onto the scene in education. As everyone who has accessed this platform knows, this has been a very important instrument in the evolution of teaching, as it has facilitated the communication between the educator and the students, especially as a space to share learning materials (Lecturer in Law).

\subsubsection{Digital material production:}

Although most participants had experience in using digital educational tools for managing and delivering their content, the use of media such as video and audio was new to many of them. The use of these new formats was a challenge for several academics:

Speaking in front of a camera was very challenging for me. I had to plan and script the recordings very well because I didn't feel that the flow of my discourse was natural. I have thousands of hours of lecturing experience, and I feel very comfortable in a lecture room full of students, but the camera was daunting!

The variety of formats was an important aim within the institution, as the instructional designer below states:

When I started in this team I saw that on-line education is more than PDF files on a Web site. On-line education means peer review, a great amount of digital formats. We were very keen on generating interactive educational resources (Instructional designer).

\subsection{Demands}

All participants recognised having received with excitement and enthusiasm the proposal to participate in MOOCs. They all saw MOOC's potential benefits for their careers, for their institution, and for the future of education. However, after their participation, they admitted that MOOCs carried a heavy workload. Not much frustration was displayed in that respect, but many of them had certain requests in case of further involvement in these projects:

\subsubsection{Incentives}

Developing MOOCs involves great investment in effort and time, and in exchange there were a few demands that educators would like to make if they had the chance:

There is a need for more support from the institution. I worked on this course intensively for several months. This task should be recognised, and rewarded with an alleviation of teaching hours at the very least (Professor in Literature).

The institution has to take into account that the efforts in a MOOCs is similar to the efforts in our face-to-face lectures (Professor in Chemistry). 


\subsubsection{More investment in resources:}

Another recurring request from educators involved in MOOCs was an increase in the resource investment, both in human and technological terms:

We are nowadays provided with many tools for generating audiovisual content, but there are many new tools out there that can be of great help to us for developing better resources (Professor in Law).

I would strongly suggest finding funding to develop these technologies with a strong investment because this would enhance the position of our university. Investing in teams' resources for the development of this kind of products is very important (Lecturer in Law).

\section{DISCUSSION}

\subsection{Challenges}

As outlined in the above section, making MOOCs carries a varied set of challenges to a Higher Education Institution and their academic staff. The complexities of interacting with wide and unknown audiences are often a challenge for educators who aim for engaged learning communities (Anderson \& Dron, 2015). Shared experiences such as that in (Sánchez-Vera, León-Urrutia, \& Davis, 2015) suggest that getting learners to participate in the forums, and manage this participation is significantly challenging. This also involves a heavy workload, as it has been observed in the statements of the participants in this study. In a survey run by the Chronicle of Higher Education, conducted when MOOCs were at their hype peak (Kolowich, 2013), most of the professors were asked whether MOOCs caused them to divert time from other activities. The majority responded that it did. In this study, most of the academics involved in the production of MOOCs both in i1 and i2 found it a stimulating and rewarding task, although it should be borne in mind that most of them already had positive attitudes towards most of the aspects of MOOCs, as all of them embarked on such an endeavour voluntarily. Nevertheless, the challenges associated to combining traditional academic duties with their newly appointed MOOC endeavour were widely mentioned. It is therefore advisable not to underestimate the amount of work involved in MOOCs, especially at strategic and senior management level.

\subsection{Opportunities}

Both the participants in this study and the researchers coincide in the belief that MOOCs are a valuable source of opportunities at individual, institutional, and social levels. With regards to the social benefits, providing free education seems not to be a top motivation in HEIs for investing in MOOCs (Davis, Dickens, León Urrutia, Sánchez Vera, \& White, 2014; León-Urrutia, White, \& White, 2016), although their potential to benefit developing countries has been discussed (Liyanagunawardena, Parslow, \& Williams, 2014; Agarwal, 2013). There are sceptical views in that respect (Rohs \& Ganz, 2015). This theme was recurrent in participants' responses, when asked what opportunities producing MOOCs can offer.

Perhaps because it may be more enticing at institutional strategic level, the digital transformation was identified as especially relevant in the study. A report by Universities UK (2013) suggests that the advent of MOOCs is a signal of a significant transforma- tion in Higher Education. The digitisation of learning materials and communication tools has played a transformative role in education since the spread of VLEs in the early 2000s (Anderson \& Dron, 2010). As observed in the results, participants tended to be experienced in the use of certain digital tools, especially VLEs. However, many of them recognised that MOOCs were a step beyond in the digital transformation of the university, in line with De Freitas' definition of MOOCs as the final frontier of Higher Education (De Freitas, 2013). In De Freitas' words, “the impact of digital technologies, digitization of content and use of social and digital media are transformative inherently, surely the goal of all universities is to share and extend knowledge to all global communities. Bearing this in mind then, the best approach to take to MOOCs and online learning in general is to be part of the revolution" (Ibid)

\subsection{Demands}

MOOCs are a highly demanding task. They require creativity, innovation, time, and a great deal of effort. Institutional support in various forms should therefore be provided from the institution to those academics that agree to be involved in the development of these kinds of courses. This need was expressed in the form of a set of demands that the participants communicated through these interviews. One of these forms of support was suggested to be a set of incentives, especially the recognition of their effort in the form of alleviation of other duties, such as lecturing time, marking, research, and administrative duties. Another common demand was an increase in the human and technical resources to assist academics in the production of digital learning content. This raises the question of whether institutional strategies allocate resources in accordance with the size of the needs of educational innovation and technology, an issue that has always been difficult to calibrate (Salmon, 2005).

\section{CONCLUSION}

This article has discussed the views held by HEIs' staff about MOOCs at their universities. From participant responses, it could be stated that those who are involved in MOOCs hold a positive attitude to this open education approach. They are keen on creating externally facing materials that showcase their work, and at the same to provide free education to those in need. They also see joining the MOOCs movement as an opportunity to smoothen the digital transformation of their university by not only keeping their digital materials in online repositories, but also organising them for repurposing and reusing, towards an optimal use of them.

However, there is a cost associated to being involved in these kinds of projects. Educators find it challenging to deliver their content in new formats, such as communicating through video, and writing for large, diverse, and unknown audiences. This often leads to academics devoting a larger amount of time and effort that is not always rewarded. It is therefore very common that they demand that their efforts be recognised in various forms such as the reduction of teaching duties. Another common demand is for more promotion of these courses, both internally and outside their institutions, in order for these courses to remain sustainable. More investment in resources for MOOCs from the institutions is also highly requested, as participants believe that they will soon become indicators of excellence. 


\section{ACKNOWLEDGMENTS}

Funded by: Ministry of Economy and Competitiveness, Spain. Funder Identifier: http://dx.doi.org/10.13039/501100003329 Award: TIN2014-52129-R

Work partially funded by the Madrid Regional Government from grant no. S2013/ICE-2715, the Spanish Ministry of Economy and Competitiveness project Flexor (TIN2014-52129-R). This research work was made possible thanks to Universidad Autónoma de Madrid, Spain and the University of Southampton, U.K.

\section{REFERENCES}

Agarwal, P. (2013). How MOOCs Can Help India. Scientific American, 2-3.

Aldred, R. (2009). From community participation to organizational therapy? World Cafe and Appreciative Inquiry as research methods. Community Development Journal, 46(1), 57-71. doi:10.1093/cdj/bsp039

Allen, I. E., \& Seaman, J. (2015). Grade level: Tracking online education in the United States. Babson Park, MA: Babson Survey Research Group.

Anderson, T., \& Dron, J. (2010). Three generations of distance education pedagogy. The International Review of Research in Open and Distributed Learning. doi:10.19173/irrodl.v11i2.865

Bulfin, S., Pangrazio, L., \& Selwyn, N. (2014). Making 'MOOCs': The construction of a new digital higher education within news media discourse. The International Review of Research in Open and Distributed Learning, 15(5). doi:10.19173/ irrodl.v15i5.1856

Daniel, J. (2012). Making sense of MOOCs: Musings in a maze of myth, paradox and possibility. Journal of interactive Media in education, 2012(3). doi: $10.5334 / 2012-18$

Davis, H., Dickens, K., León Urrutia, M., Sánchez Vera, M. del M., \& White, S. (2014). MOOCs for Universities and Learners An analysis of motivating factors. In Proceedings of the 6th International Conference on Computer Supported Education. Barcelona. Retrieved from http://eprints.soton.ac.uk/363714/1/DavisEtA12014MOOCsCSEDUFinal.pdf

De Freitas, S. I. (2013). MOOCs: The Final Frontier for Higher Education? (Research Report). Coventry, UK: Coventry University. Retrieved from http://researchrepository.murdoch.edu.au/id/eprint/28971/1/MOOCS report.pdf

Hollands, F. M. (2014). Why do institutions offer MOOCs? Journal of Asynchronous Learning Network, 18(3). doi:10.24059/olj.v18i3.464

Hollands, F. M., \& Thirthali, D. (2014). MOOCs: Expectations and reality (Report). New York: Center for Benefit-Cost Studies of Education, Columbia University. Retrieved from http://cbcse.org/wordpress/wp-content/uploads/2014/05/ MOOCs Expectations and Reality.pdf

Jansen, D., \& Schuwer, R. (2015). Institutional MOOC strategies in Europe. Status Report Based on a Mapping Survey Conducted in October-December 2014. Mimeo (Report). European Association of Distance Teaching. Retrieved from https://www.surfspace.nl/media/bijlagen/artikel-1763-22974efd1d43f52aa98e0ba04f14c9f3.pdf

Jansen, D., Schuwer, R., Teixeira, A., \& Aydin, C. H. (2015). Comparing MOOC Adoption Strategies in Europe: Results from the HOME Project Survey. The International Review of Research in Open and Distributed Learning. doi:10.19173/ irrodl.v16i6.2154

King, N. (1998) Template Analysis. In G. Symon \& C. Cassell (Eds.), Qualitative methods and analysis in organizational research: A practical guide, (pp. 118134). Thousand Oaks, CA: Sage Publications.

Kolowich, S. (2013, march 18). The Professors Behind the MOOC Hype [Web log message]. The Chronicle of Higher Education. Retrieved from https://www. chronicle.com/article/The-Professors-Behind-the-MOOC/137905

Kolowich, S. (2014, august 08). The MOOC "Revolution" may not be as disruptive as some had imagined [Web log message]. The Chronicle of Higher Education. Retrieved from http://chronicle.com/article/MOOCs-May-Not-Be-So-Disruptive/140965/

León-Urrutia, M. White, S., \& White, S. (2016). MOOCs in higher education magazines: a content analysis of internal stakeholder perspectives. In S. Zvacek, M. T. Restivo, J. Uhomoibhi, \& M. Helfert (Eds.), Computer Supported Education: 7th International Conference, CSEDU 2015, Lisbon, Portugal, May $23-$ 25, 2015, Revised Selected Papers (pp. 395-405). Cham: Springer International Publishing.

Liyanagunawardena, T. R., Parslow, P., \& Williams, S. A. (2014). Dropout: MOOC Participants' Perspective. In Proceedings of the European MOOC Stakeholder Summit 2014 (pp. 95-100). Retrieved from http://centaur.reading.ac.uk/36002/

Newton, N. (2010). Exploring Qualitative Methods: The use of semi-structured interviews. Exploring Qualitative Methods, 1-11.

O'Connor, K. (2014). MOOCs, institutional policy and change dynamics in higher education. Higher Education, 68(5), 623-635. doi:10.1007/s10734-014-9735-z
Pappano, L. (2012, november 2). The Year of the MOOC. The New York Times. Retrieved from http://www.nytimes.com/2012/11/04/education/edlife/massiveopen-online-courses-are-multiplying-at-a-rapid-pace.html

Rohs, M., \& Ganz, M. (2015). MOOCs and the claim of education for all: A disillusion by empirical data. International Review of Research in Open and Distance Learning, 16(6). doi:10.19173/irrodl.v16i6.2033

Salmon, G. (2005). Flying not flapping: a strategic framework for e-learning and pedagogical innovation in higher education institutions. ALT-J, 13(3), 201-218. doi:10.3402/rlt.v13i3.11218

Sánchez-Vera, M. M., León-Urrutia, M., \& Davis, H. (2015). Challenges in the Creation, Development and Implementation of MOOCs: Web Science Course at the University of Southampton. Comunicar, 22(44), 37-44. doi:10.3916/C442015-04

Shah, D. (2017). MOOC Course Report: January 2017. Retrieved from https://www. class-central.com/report/mooc-course-report-january-2017/

Sharrock, G. (2015). Making sense of the MOOCs debate. Journal of Higher Education Policy and Management, 37(5), 597-609. doi:10.1080/136008 0X.2015.1079399

Universities UK. (2013). Massive open online courses: higher education's digital moment? London, UK. Retrieved from http://www.universitiesuk.ac.uk/policy-and-analysis/reports/Documents/2013/massive-open-online-courses.pdf

How to cite this article: León-Urrutia, M., Cobos, R., \& Dickens, K. (2018). MOOCs and their Influence on Higher Education Institutions: Perspectives from the Insiders. Journal of New Approaches in Educational Research, 7(1), 40-45. doi: 10.7821/naer.2018.1.252 